\title{
MÚSICA Y CAFÉS SALMANTINOS A COMIENZOS DEL S. XX, A TRAVÉS DE LA PRENSA LOCAL
}

\author{
Music and Cafés in Salamanca at the Beginning of the 20th Century \\ Through the Local Press
}

Francisco José Álvarez García Universidad Pontificia de Salamanca

fjalvarezga@upsa.es

Fecha de recepción: 16-X-2012

Fecha de aceptación: 24-X-212

Resumen: La música de café es uno de los géneros más populares en la Europa de comienzos del S. XX. Músicos, pequeñas compañías, agrupaciones de diversa tipología, tunas, etc., se dan cita en este tipo de locales para dar a conocer su repertorio pero sobre todo ofreciendo el que, junto con el teatro, será el principal medio de entretenimiento social: El Concierto de Café.

Salamanca, como capital de provincia, no podía ser menos. De este modo, en el presente artículo, encontramos siete representantes importantes del citado género

Palabras clave: Café Musical, Salamanca, S. XX, Música.

Aвstract: Music Coffee is one of the most popular genres in Europe early S. XX. Musicians, small companies, diferents kind of groups, tunas, etc.., come together in such premises to present their repertoire but mostly offering which, along with the theater, will be the main form of social entertainment: The coffee concert.

Salamanca, as provincial capital, is to be expected. Thus, in this article, find seven important representatives of that genre.

Keywords: Coffee concert. Salamanca, 20th Century, Music. 


\section{INTRODUCCIÓN}

Desde media tarde, Salamanca ofrecía, a comienzos de siglo a sus ciudadanos, la posibilidad de distraerse en un variado grupo de locales, cafés, bares y salones donde, además de participar de una conversación animada sobre política, educación o toros, (regada, cómo no, con un buen chato de vino o un café), se podía también disfrutar de un variado repertorio musical, ofrecido por multitud de agrupaciones e intérpretes (locales o foráneos), que encontraban en este tipo de establecimientos, una forma de ganarse la vida o de complementar una profesión, (normalmente la de profesor de música), que, en la mayor parte de los casos, no era suficiente, económicamente, para llevar una vida acomodada. Algunos de estos locales se convirtieron (o ya lo eran a comienzos de siglo), en referentes musicales a los que acudir para escuchar a un buen guitarrista, pianista, quinteto de cuerda, violinista, arpista, sexteto, etc., especializándose cada uno de ellos en determinados géneros, contribuyendo así a seleccionar, de algún modo, el tipo de clientela. Normalmente los cafés que incluían asiduamente números musicales, estaban vinculados a una clase social media-alta ya que, el resto, no podían permitirse el desembolso inicial derivado de la contratación de los mismos.

Los regentes de este tipo de locales, tenían muy en cuenta el tipo de espectáculo musical que ofrecían ya que, en gran parte, de éstos dependía la afluencia de gente a los mismos, repercutiendo directamente en la caja y en los ingresos a obtener, por tarde-noche.

La calidad de este tipo de espectáculos no siempre era buena, aunque, en general, debemos decir que, según las críticas, muchas de las agrupaciones o participaciones de músicos individuales estaban formadas por distinguidos profesores o concertistas consumados, que ofrecían la mayor parte de las veces excelentes conciertos, con una gran variedad de programa y repertorio. Bien es cierto que no en todos los locales ni en cualquier temporada, la participación musical estaba asegurada; pensemos que ésta, se intercalaba con actuaciones no musicales de todo tipo, muy atrayentes también para la clientela, como las verificadas por ilusionistas, malabaristas, transformistas, bailarines, equilibristas, etc., que también hacían su Agosto en varios locales de la ciudad.

La temporada y estación en la que nos encontremos, también es importante para enmarcar una tipología de espectáculo musical concreto. Determinados locales que cuentan con patios interiores o terraza, condensaban sus esfuerzos en organizar eventos con el buen tiempo, en primavera y verano, mientras que locales amplios pero sin patio, utilizaban la temporada de otońo e invierno para atraer al público al son de la música, amén de una buena calefacción, (importantísima para que la clientela acudiera). Las campańas en las que no encontramos teatro o zarzuela en alguno de los teatros salmantinos, también se cuentan entre las ocasiones más apropiadas para contratar músicos que amenicen el café o salón, ahogando de este modo las ansias líricas de los contertulios. 
Con la progresiva generalización del cinematógrafo en muchos cafés y salones de recreo salmantinos y, sobre todo, a partir de la segunda mitad de la década a estudio (1900-1910), al contrario de lo que se podría pensar en un principio, los espectáculos musicales y de varietés se multiplican, adquiriendo un renovado protagonismo. En multitud de ocasiones, son utilizados como reclamo e intermedio vistoso a un creciente público que empieza a convertirse en asiduo al celuloide. No será hasta la siguiente década (1910-1920), cuando veamos verdaderamente relegados a un segundo plano los números y participaciones musicales de los cafés y salones salmantinos, a causa del ímpetu y auge del cine. Por otra parte, los cafés y locales de esta tipología son los que, a través de diferentes contrataciones, contribuyen a la formación de músicos y agrupaciones que después, llegan a constituirse en elementos significativos del panorama musical salmantino. De esta forma, muchas de las agrupaciones importantes que se describen en el presente artículo, así como gran parte de los músicos relevantes, han surgido o se han dado a conocer perteneciendo a un determinado lugar de esparcimiento o café, como «El Sexteto del Pasaje» en el «Café Pasaje», dirigido en su última formación por Hilario Goyenechea, las diferentes Tunas Escolares con el café «El Suizo» o «El Septimino» del Novelty.

Pasemos a ver con detenimiento los cafés y lugares de esparcimiento más importantes a comienzo del S. XX, en Salamanca:

\section{CAFÉ DEL PASAJE}

Situado en la Plaza Mayor, en el popular paseo de Correos, haciendo esquina con el actual pasaje de la Caja de Ahorros, el café del Pasaje formaba parte de las instalaciones correspondientes al también denominado «Hotel del Pasaje» (Plaza Mayor, 39.), regentado durante los once ańos sobre los que versa el presente artículo, por el empresario Marcelino Chapado. Se trata de un local muy espacioso a tenor de lo que sustraemos de diferentes referencias en prensa, en los que se nos reseńa la amplia capacidad del local y se nos describen las veleidades del gran salón y de su patio interior, apreciado sobre todo, durante las noches estivales.

\section{(...) Y contribuye mucho a realzar la nota simpática la frescura del patio en que se verifican los conciertos. Se respira ambiente fresco y perfumado, se conversa franca y cordialmente con los cotidianos contertulios entre sorbo y sorbo del aromático moka, y de media en media hora las conversaciones se interrumpen para oir y escuchar las delicadas notas del sexteto que con gusto y afinación interpreta escogidas obras de los más notables compositores ${ }^{1}$.}

\footnotetext{
«Salamanca», El Lábaro -Salamanca-, 3 de Agosto de 1907; B.G.U.S.
} 
Es precisamente este patio interior, junto con la posibilidad de sacar mesas a la acera colindante al café, en el paseo de Correos, uno de los platos fuertes del local, situado en pleno centro de la ciudad, en la propia Plaza Mayor. Esta cercanía con el centro neurálgico de la ciudad, convierte al café en un lugar estratégico para sentarse en sus veladores a disfrutar, los jueves y domingos estivales, de los conciertos que la banda «El $1^{\circ}$ de Mayo» o la "Provincial», ofrecen en el templete. Este tipo de participaciones dan pie a establecer en la propia Plaza Mayor, una auténtica pirámide social donde, las diferentes clases salmantinas, se colocan alrededor del kiosco de la música, atendiendo a una determinada posición y escalafón social. Así, los afortunados situados en la terraza del Pasaje, demuestran una posición social más acomodada que los que escuchan o pasean simplemente sin el placer de disfrutar de un refrigerio. Precisamente a causa de su magnífica terraza, la mayor parte de la actividad musical del café Pasaje, se registra los meses de verano, sobre todo entre Julio y Agosto, aunque el café no interrumpe del todo sus conciertos el resto del año, sorprendiéndonos, de vez en cuando, con la participación de algún músico o agrupación, por ejemplo la rondalla de «los Hijos del Trabajo».

Pasemos a estudiar, año por año, la actividad musical recogida en prensa durante los once años que abarca el presente estudio:

a.) 1900: Sin actividad musical. Ninguna noticia en todo el ańo sobre actividad musical en el café, aunque sabemos que el local estaba en funcionamiento y era bien conocido en Salamanca.

b.) 1901: Máxima actividad musical durante el mes de Julio cuando fueron contratados Jacinto y Mariano Rodríguez y el maestro Reñones para amenizar las noches estivales. El trío estaba compuesto por el pianista Julio Reñones, el violinista, Jacinto Rodríguez, y al contrabajo, el padre de este último, Manuel Rodríguez; los tres, conocidísimos músicos en la Salamanca de comienzos de siglo, como en cada capítulo correspondiente a cada músico, consignaremos. Los conciertos, que se celebraron prácticamente a diario, de nueve a once, obtuvieron una muy buena crítica, teniendo que repetir cada noche, prácticamente, la totalidad del programa. El repertorio de los recitales estaba compuesto, principalmente, por pasodobles tradicionales y arreglos de partes instrumentales, cuplés y coros de conocidas zarzuelas. También abundaban las «fantasías» sobre motivos de óperas famosas conocidas por el público salmantino y alguna que otra pieza del repertorio clásico-romántico (nocturnos, suites, etc).

c.) 1902: Actividad musical de Julio a Octubre del trío formado por Jacinto y Manuel Rodríguez y Julio Reñones, aparte de una intervención puntual de la Rondalla «Hijos del Trabajo», en Febrero. La recepción del público, tan buena como en la temporada anterior, obteniendo muy buena crítica en todas las actuaciones.

d.) 1903: Sin actividad musical relevante. 
e.) 1904: Actividad musical durante la primera semana de Julio, por parte de la guitarrista Purificación Cots. Tras su corto paso por el Pasaje, pasó a actuar al salón Variedades. No disponemos de repertorio ni críticas a su actuación.

f.) 1905: Sin actividad musical relevante.

g.) 1906: Sin actividad musical relevante.

h.) 1907: Actividad musical de Julio a Diciembre, de manera prácticamente continuada, además de una participación puntual en Febrero de la Tuna Escolar, dirigida, ese año, por el violinista Eloy Andrés. Los meses de verano y otońo, estuvieron cubiertos íntegramente, con la participación de una nueva agrupación que se convertiría, con el paso de las semanas, en uno de los conjuntos más populares de la capital: El sexteto del Pasaje:

Deseando obsequiar el señor Chapado, dueño del Café del Pasaje a sus parroquianos, ha contratado un sexteto formado por distinguidos profesores de esta localidad, para dar conciertos por las noches en el hermoso patio que existe en este Café; hemos asistido a un ensayo del sexteto y podemos decir que los aficionados a la buena música, están de enhorabuena, tan por la valía de las obras como por su buena ejecución (... $)^{2}$.

El sexteto, que modificó su composición varias veces a lo largo de su historia, estaba formado originalmente por:

He aqui el personal del sexteto de los conciertos que se han de verificar en el Café del Pasaje: Primer violin: Jacinto Rodríguez; Segundo violin: Manuel Mezquita; Viola: Fernando Rodríguez; Violoncello: Enrique V. Mezquita; Contrabajo: Manuel Rodríguez; Pianista: Julio Reñones. .

Como observamos, el sexteto estaba apoyado en el trío formado por los profesores Manuel y Jacinto Rodríguez (padre e hijo), acompañados del maestro Julio Reñones, intérpretes asiduos del café desde años atrás. El resto de componentes, como comprobaremos al abordar a cada instrumentista en su capítulo correspondiente, son reputados profesores y conocidos músicos locales. ${ }^{4}$ La recepción por parte del público fue muy buena y su continuidad, más allá de la temporada estival, demuestra que fue gratamente recibido, ausentándose tan sólo parte del mes de Septiembre, tras ser contratado por un café de Béjar. Los programas, estaban formados por fragmentos y adaptaciones de

2 «Noticias», El Adelanto -Salamanca-, 25 de Julio de 1907; B.G.U.S.

3 «Noticias», El Adelanto -Salamanca-, 30 de Julio de 1907; B.G.U.S.

4 ALVAREZ GARCÍA, F. J.: «Músicos en Salamanca a comienzos del S. XX». Publicaciones Universidad Pontificia de Salamanca. Salamanca, 2012 
zarzuelas y óperas populares, valses y números clásicos mezclados con algún que otro pasodoble. Tras la temporada veraniega, el profesor Fernando Rodríguez fue sustituido a la viola por R. Cea.

i.) 1908: Actividad musical durante el mes de Julio y Agosto. El consolidado sexteto, como el año anterior, fue el encargado de amenizar las noches veraniegas con una composición idéntica a la original, volviendo a ocupar la viola el profesor Fernando Rodríguez en sustitución, nuevamente, de R. Cea. Además, el gerente del café, Manuel Chapado, realizó reformas en el local, con la intención primera de atraer nuevo público al café, añadiendo iluminación al patio y ornamentándolo. También comenzó a repartir programas de los conciertos impresos, que fueron muy del agrado de la audiencia:

\section{(...) Entre el auditorio, se repartieron por la casa Chapado elegantes carnets anunciadores del programa musical de esta noche, que es el siguiente: (... .).}

La recepción del público, como en anteriores ocasiones, fue muy buena, registrándose llenos casi todas las noches y siendo los profesores aplaudidos en cada recital. Las audiciones se verificaban cada noche de nueve a once, como hasta ahora venía siendo habitual. Los programas, como siempre, mezclaban repertorio zarzuelístico, fantasías románticas y posrománticas y algún que otro pasodoble:

\section{(...) Programa para hoy: "Zampa». Sinfonía. Herold. "Dúo de la africana». Caballero. "Alma de Dios» (canción húngara). Serrano. "Fausto» (fantasía). Gounod. "Souvenir de abril». Georges. Anoche estuvo muy animado y gustó mucho, haciéndole repetir "alma de Dios", que tan buen éxito está dando en Madrid'.}

j.) 1909: Actividad musical en Marzo, con la participación de los profesores Hilario Goyenechea al piano y Jacinto Rodríguez al violín y, como es costumbre, reinauguración de los clásicos recitales estivales, este año en Agosto, un mes más tarde de lo habitual, abriéndose la temporada con la transformación del famoso sexteto en un quinteto, comandado esta temporada por el mismo Hilario Goyenechea. El programa de los conciertos celebrados en Marzo, por el reputado dúo de profesores estaba basado, como en ocasiones anteriores, en repertorio zarzuelístico, fantasías y adaptaciones de autores románticos. También encontramos obras de Felipe Espino y del propio Hilario Goyenechea. El quinteto (si consideramos la participación de Luis Martín, no consignado en prensa en esta ocasión, pero habitual de la agrupación), estaba formado por los profesores siguientes: Hilario Goyenechea (al piano), Manuel y Jacinto Rodríguez, (contrabajo y violín) José Mezquita (viola) y Luis Martín (violonchelo)

\footnotetext{
5 «Noticias», El Adelanto -Salamanca-, 2 de Agosto de 1908; B.G.U.S.

6 «Noticias», El Adelanto -Salamanca-, 9 de Julio de 1908; B.G.U.S.
} 
Como teníamos anunciado al público, hoy lunes, a las nueve y media de la noche, darán principio los conciertos en el patio del Pasaje, por el notable quinteto salmantino compuesto por los señores don Hilario Goyenechea, don Manuel Rodríguez, don Jacinto Rodríguez y don José Mezquita, los que prometen dar a conocer al público un escogido repertorio ${ }^{7}$.

k.) 1910: Actividad musical en la temporada de verano, durante los meses de Julio y Agosto, por el quinteto de Hilario Goyenechea, como ya es conocido por la prensa ese año. La composición de la agrupación experimentó algunos cambios consolidándose de la siguiente manera:

Hoy miércoles a las nueve y media de la noche, darán principio los conciertos, por el notable quinteto que dirige el Maestro señor Goyenechea: Primer violin, Jacinto Rodríguez; segundo violin, José Mezquita; viola, Luis Martín; contrabajo, Rafael Rodríguez; pianista, Hilario Goyenechea (... $)^{8}$.

Durante los meses de Octubre, Noviembre y Diciembre, la agrupación, constituida, como en sus orígenes, en sexteto y comandada por el propio Hilario Goyenechea, pasó a actuar, por primera vez, en el Casino de Salamanca, adquiriendo, si cabe, más fama aún de la adquirida hasta entonces.

\section{CAFÉ DEL SIGLO}

Situado en el número 3 y 5 principal de la calle Prior, el Café del Siglo fue, sin duda, uno de los referentes artístico musicales más importantes de la Salamanca de comienzos de siglo. A caballo entre café y salón de variedades, sus amplios salones situados en dos plantas, albergaban desde recitales vocales e instrumentales, hasta la representación de pequeñas zarzuelas, pasando por todo tipo de números de varietés, como cupletistas, transformistas, bailarines, etc. En cuanto a su gestión, el local ha pasado por muchos dueños, bastantes denominaciones y multitud de usos. Desconocemos el nombre de su regente a comienzos de siglo, aunque sabemos que en la primera semana de 1902, el local fue traspasado a los empresarios del Kana Klub (antigua sala de baile) que, por otra parte, regentaban el salón Artístico y el Bretón (por temporadas). Éstos se encargaron, desde su adquisición, principalmente, a la organización propia de su especialidad: bailes para las clases obreras y artesanas.

Hasta entonces, el local, que también había albergado bailes, estuvo más dedicado a la presentación de zarzuelas reducidas, no en extensión sino en número de componentes (muchas veces sin ningún elemento en el coro y con no más que un piano o trío de

\footnotetext{
7 «Los conciertos del Pasaje», El Adelanto -Salamanca-, 2 de Agosto de 1909; B.G.U.S.

8 «Noticias», El Adelanto -Salamanca-, 13 de Julio de 1910; B.G.U.S.
} 
músicos en el acompańamiento instrumental). En esta primera etapa, el nombre completo del café era "Café Teatro del Siglo», circunstancia que nos pone en tesitura de la actividad principal habitual en el mismo:

El cuadro de zarzuela que actúa todas las noches en el Café del Siglo es muy aceptable y el local se ve completamente lleno durante todas sus funciones. Anoche se pusieron en escena «El Monaguillo» y "La buena sombra» y los modestos artistas encargados de su ejecución fueron muy aplaudidos?

Los precios por sesiones eran realmente reducidos, en comparación con los existentes en Liceo y Bretón aunque, claro está, la presentación del espectáculo, evidentemente, no estaba a la altura, ni mucho menos, de lo encontrado en los teatros de la capital, aunque, bien es cierto que algunas compañías de zarzuela que actuaban asiduamente en el Siglo, representaban también, esporádicamente en los teatros locales y de la provincia: «(...) Entrada general a cada sección 25 cts. (...)» $»^{10}$.

Los empresarios del café, cambiaron de nombre al establecimiento, que pasó a denominarse "Variedades» o "Salón Teatro Variedades» (aunque durante unos meses, en prensa siguió compartiendo la nueva denominación con la de «Café del Siglo). Realizaron varias transformaciones en los salones, sobre todo en el local principal, en la planta baja, aumentando considerablemente la popularidad del mismo que, desde Marzo o Abril, se amplió con un nuevo servicio de café y la propia redecoración del local. A finales de 1902, la naciente sociedad "Unión Mercantil y Escolar», arrienda el local para la temporada de bailes de invierno. Durante 1903 y 1904 la actividad, dirigida por los empresarios del Kana Klub, se circunscribió sobre todo a la celebración de bailes en carnaval, Navidad y otras fiestas populares para, de manera principal, la clase obrera y artesana. También encontramos reuniones de confianza organizados directamente por la empresa, para socorrer a obreros y artesanos desfavorecidos por diversas circunstancias, así como actuaciones musicales de diverso género. En Octubre de 1904, tenemos constancia de la vuelta de la zarzuela de la mano de la compañía de Antonio Nicuesa, que durante el invierno, y aprovechando la sequía lírica del Liceo y Bretón, representaba una zarzuela por sección al módico precio de 25 céntimos (la entrada en el Liceo rondaba la peseta ó 0,75 céntimos en sección sencilla). La empresa realizó de nuevo mejoras en el local:

En breve comenzará a actuar en el Salón Variedades la compañía de zarzuela chica que dirige el señor Nicuesa, la cual se propone durante el invierno, representar las mejores obras de su repertorio. Para ello la empresa que lo ha tomado a su cargo está introduciendo mejoras' ${ }^{11}$.

\footnotetext{
9 «Crónica Local y Provincial», El Adelanto -Salamanca-, 27 de Abril de 1900; B.G.U.S.

10 «Sección de Espectáculos», El Adelanto -Salamanca-, 29 de Octubre de 1904; B.G.U.S.

11 «Sección de Espectáculos», El Adelanto -Salamanca-, 28 de Octubre de 1904; B.G.U.S.
} 
Las críticas a la labor de la compañía fueron bastante buenas y lograron permanecer en el Variedades hasta final de año, representando más de 35 zarzuelas diferentes y estrenando la zarzuela de "La Indiana». Al finalizar el año, tomó el relevo la compañía de zarzuela de José Hidalgo, representando género chico en tres secciones hasta finales de Febrero. La compañía cambio de titularidad en Enero, pasándose a denominar «Compañía Muñoz», conservando todos los actores y actrices anteriores. A partir de Febrero y con la llegada de los carnavales, la empresa abrió un nuevo salón en la planta superior, que permitía simultanear zarzuela y baile en la misma temporada, haciendo crecer la popularidad del local. También se utilizó la nueva estancia para celebrar conciertos instrumentales, en este caso, seguramente, verificado por el que más adelante será conocido como «Sexteto del Pasaje». A finales de 1905, se creó la «Sociedad Juvenil», con el propósito de organizar una serie de bailes en el Variedades, concretamente en su salón principal, que se prolongaron, junto con los de otras asociaciones como la "Juventud Hortera» o la «Unión Juvenil», hasta 1906. Quizá sea esta la época en la que el Variedades registró más actividad en el género.

Durante 1906, nuevas sociedades utilizaron los salones del Variedades para organizar sus bailes de confianza, como la "Juventud Mercantil», formada por dependientes de comercio, o la "Juventud Artesana». La trascendencia tanto de estas dos sociedades, como la de las presentadas con anterioridad, nunca implicarán nada más allá de la celebración de estos propios bailes de campaña concreta, ya fueran por ferias, carnavales o Navidad. Pero sin duda, la transformación más importante tanto estética, como de género, que se produjo en Variedades, vino de la mano del cinematógrafo, que suprimió prácticamente por completo las representaciones teatrales líricas, al trasformar el escenario por completo, volviendo a convertir el local en salón de varietés dominado por cupletistas, bailarines y artistas de diversa índole. Los bailes de confianza también se redujeron en número, circunscribiéndose prácticamente al periodo carnavalesco y de feria.

\begin{abstract}
El día $1^{\circ}$ de Agosto se inaugurará en el salón de Variedades, Prior 3 y 5 principal, elegantemente acondicionado, el gran cinematógrafo de Madrid (Centenera y Compañia), cuya empresa se propone dar a conocer en Salamanca cuantas novedades y maravillas modernas completan los últimos adelantos cinematográficos ${ }^{12}$.
\end{abstract}

Esta transformación se acentuó a finales de 1907 cuando, al amparo de un nuevo empresario, el popular «Jiti» o "Jitiván», el Variedades, que estrena nombre, coincidiendo con la instalación de un nuevo cinematógrafo mejorado, pone todo su empeńo en volver a colocar al pequeño número de «varieté musical» en su sitio. Es el turno de «El Palacio de la Ilusión»:

12 «Noticias», El Adelanto -Salamanca-, 30 de Julio de 1906; B.G.U.S. 
El Palacio de la Ilusión. Ayer hizo su debut en el Salón Variedades, un cinematógrafo que merece en honor a la verdad que el público lo visite con frecuencia $(. . .)^{13}$.

A finales de Marzo, el Palacio de la Ilusión fue clausurado por orden gubernamental, al no cumplir una serie de requisitos impuestos por Juan de La Cierva, ministro de instrucción pública. Durante un mes, el local no ofreció ningún tipo de función (cinematográfica o no), hasta su reapertura, ya a finales de Abril, con la misma tipología de espectáculo: cine y variedades musicales.

No estamos muy sobrados de diversiones que digamos. Cerrado el cine de la calle del Prior, para cumplir de este modo las órdenes de LaCierva, que exige a los peliculeros una serie de cosas que asustan, no queda lugar donde pasar unas horas de distracción honesta (... $)^{14}$.

En Junio de 1908 encontramos una nueva compañía de zarzuela chica que dejará descansar a los números de variedades y cinematógrafo, hasta la primera semana de Julio. La formación no estrenó ninguna zarzuela, representando tan sólo 13 obras en las tres semanas que permanecieron en el salón, obteniendo buena crítica en general. Tras el cierre del local y la posterior participación de la compañía de zarzuela chica de Francisco Macías, los números de variedades se suavizaron bastante en "forma y fondo» para adaptarse a las nuevas directrices venidas de Madrid. Este cambio fue perfectamente identificado por la prensa:

(...) Decididamente ha cambiado por completo el aspecto de este salón de recreo. A los couplets cargados de pimienta de las artistas que han desfilado por el escenario del Palacio de la Ilusión, han sucedido los números finos y elegantes y que han de servir de solaz esparcimiento al público selecto de Salamanca. Prueba de ello es que la preferencia se ve todas las noches totalmente ocupadas por distinguidas señoritas. La empresa, agradecida a esta deferencia del público salmantino, no ha reparado en sacrificios, y ha contratado a varios artistas que, como los que ahora se exhiben, presentan un espectáculo culto. El trío Lucerito, que hizo su debut el sábado, lo forman tres niñas, cuya presentación en escena causó una grata impresión en el público. Las tres jovencitas ejecutan preciosos bailables. Además acompañan con panderos otras piezas de música, siendo por su labor muy aplaudidas. (... $)^{15}$.

Con el tiempo, los cuplés y los bailes se fueron volviendo cada vez más intencionados, sobre todo a última sesión, pero esta vez no hubo cierre de local, sino una sencilla reprimenda por parte de El Lábaro, mucho más conservador que El Adelanto:

\footnotetext{
13 «De Espectáculos», El Adelanto -Salamanca-, 5 de Noviembre de 1907; B.G.U.S.

14 «De Espectáculos», El Adelanto -Salamanca-, 20 de Marzo 1908; B.G.U.S.

15 «Palacio de la Ilusión», El Adelanto -Salamanca-, 12 de Octubre de 1908; B.G.U.S.
} 
¿Quépasó? Hace muy pocas noches abandonaron precipitadamente la localidad de preferencia del Cinematógrafo de Variedades varias señoras que alli se encontraban en la última de las sesiones que se celebran. Hemos oido decir que los couplets que se cantaban eran el colmo de la bestialidad. Aplaudimos la conducta del jefe de vigilancia Sr. Comerón, que, según nuestras noticias, mandó retirar del programa esos couplets, impidiendo su repetición ${ }^{16}$.

En semanas sucesivas van pasando por el salón multitud de intérpretes, sobre todo cupletistas, que van haciendo las delicias del público. También se realizan nuevas obras y el cinematógrafo parece haber quedado relegado a un segundo plano. Las intervenciones instrumentales fueron desplazadas en parte, a su vez, por los propios números de variedades, cada vez más populares y de mayor repercusión mediática. En Enero de 1909 y sin motivo aparente, la prensa deja de identificar al salón del popular «jitiván» como «Palacio de la Ilusión», pasando a ser denominado, de nuevo, «Variedades». Las referencias al Variedades crecen entonces exponencialmente, encontrando espectáculo musical en prácticamente los 24 meses existentes desde Enero de 1909, hasta Diciembre de 1910, con gran variedad de producción musical, (aunque destacando, de nuevo, las cupletistas). Paralelamente al resurgir de la canción española y los cuplés, de la mano de cantantes muchas veces de prestigio, el gerente de Variedades, el señor "Jitiván», realiza de nuevo reformas en Septiembre de 1909, convirtiendo el salón en un pequeńo teatro al ampliar el escenario, que había sido reducido tras la incorporación del cinematógrafo. La actividad musical en los meses de Noviembre y Diciembre de 1909 en Variedades es diaria, con multitud de referencias en prensa. La crítica a la mayor parte de los espectáculos no pasa de regular, aunque algunas cupletistas, según El Adelanto, dan la talla:

\section{(...) En varietés también hemos visto un sin número de artistas, unos buenos como los ven- trílocuos señores Juliano y Serra, y las coupletistas y bailarinas la Americanita, bella Dora, Violeta y bella Bilbao, hermanas Cheray y tantas otras. Hemos tenido regularcitas y malas que a los dos dias han liado el petate y se han largado (... $)^{17}$.}

En Febrero de 1910, el salón pasa a llamarse "Cine Salmantino», coincidiendo con la llegada de un nuevo empresario que toma en arriendo el famoso local: Marcelino Herrero. El empresario se propone volver desterrar la «sicalipsis» y la falta de moral que hasta ahora había reinado, sobre todo de la mano de populares bailarinas y cupletistas, ofreciendo un espectáculo apto para las conciencias más limpias. En las primeras semanas la empresa comienza cosechando éxitos y buena entrada, pero pronto cuenta con la desazón del público que bien acostumbrado a la «sicalipsis» tradicional del Variedades, bien atraído por espectáculos al margen, como el carnaval, bailes, teatros, etc., abandona al nuevo empresario y dejando la sala de nuevo vacía durante más de un mes, hasta que es

\footnotetext{
16 "Gacetilla Local», El Lábaro -Salamanca-, 30 de Octubre de 1908; B.G.U.S.

17 «El año cinematográfico», El Adelanto -Salamanca-, 1 de Enero de 1910; B.G.U.S.
} 
de nuevo arrendada (suponemos que al popular "Jitiván»), por una empresa madrileńa. El local pasa a denominarse, otra vez, «Salón Variedades». La nueva empresa retoma el subarrendamiento a diferentes sociedades de baile que alquilan los locales del Variedades, para celebrar sus bailes de sociedad. En la última temporada de 1910 (otońo-invierno), el salón pasa a denominarse "Cine Variedades», cobrando importancia el cinematógrafo frente a las funciones musicales de variedades, de capa caída tras el aluvión de música registrado en los teatros, sobre todo en el Moderno que, casi todo el año ofrece zarzuela al público salmantino a precios bastante económicos. Este hecho no hizo desaparecer de las tablas del salón, por completo, los números musicales, que contaron con excepciones tan honrosas como la de la cupletista Edelmira Sandoval, una de las artistas con mejores críticas en la historia del salón. Octubre, Noviembre y Diciembre de 1910, no registraron actividad musical en el Variedades.

\section{CAFÉ CASTILLA}

Situado en los números 12-14 de la calle Toro, el Café Castilla, perteneciente al hotel homónimo, fue, durante la primera década del S.XX., uno de los locales más vinculados con la actividad musical de la ciudad, ofreciendo conciertos de reputados profesores salmantinos y de fuera. Dirigido de 1900 a 1911 por doña Juana Moreno, (viuda desde 1903), el café se preocupaba por ofrecer distracción solaz a cuantos contertulios acudieran a pasar el rato y charlar en buena compañía. El café poseía, al margen del hotel, un gran salón y un amplio reservado donde se realizaban reuniones de todo tipo, como por ejemplo, en varias ocasiones, las verificadas para las cíclicas constituciones de la Tuna Escolar, por los estudiantes salmantinos, en Noviembre y Diciembre.

\section{(...) El café era un salón hermoso, bien decorado, con grandes espejos y divanes de peluche rojo. Las mesas, de mármol blanco y bonito artesonado. En el centro del salón, formando un cuadrilátero, tenía cuatro columnas, y junto a ellas cuatro bellas estatuas de bronce, con sus pedestales de nogal macizo. Al fondo del café estaba el mostrador, muy capaz, con su artística estantería de nogal tallado y entrepaños de mármol (... $)^{18}$.}

El café estaba, de esta forma y a través de la participación de la Tuna Escolar, muy vinculado sentimentalmente a la Universidad y al ámbito estudiantil. A diferencia del Café del Pasaje, al carecer de patio, el Castilla limitaba sus propuestas musicales principalmente a los meses de otońo, invierno y primavera, utilizando el reclamo de la calefacción y la buena música como aliciente para que la clientela visitara el local. Incluso así, encontramos también actuaciones esporádicas en Junio y Julio. La clientela del café es de

18 ANSEDE, C. R.: «De la Salamanca de ayer: usos, costumbres, recuerdos...» Salamanca: Diputación de Salamanca, 1969. 
clase media-alta y el tipo de espectáculos ofrecidos no se sale, como en otros locales, del repertorio musical culto, obviando participación de excéntricos musicales, cupletistas y otros artistas no músicos, tan propios del Variedades, por ejemplo.

Quizá el músico salmantino más vinculado a comienzos de la primera década del siglo al Castilla sea Manuel Mezquita (padre) que, tras 15 años tocando en el café Suizo, fue contratado por el marido de Juana Moreno, (aún responsable del mismo, antes de fallecer), para amenizar al piano las noches primaverales. Manuel Mezquita, fue, además, hasta su muerte, en Octubre de 1903, director de la Banda Provincial (también conocida como del Hospicio o de la Beneficencia) ${ }^{19}$.

Manuel Mezquita no ofrecía únicamente recitales de piano en solitario, sino que acompañaba a otros artistas y agrupaciones en su paso por el café. Podemos afirmar que la contratación de Mezquita fue de alguna forma permanente como pianista concertador y acompañante, siendo el resto de contrataciones simplemente temporales.

La agrupación esporádica de paso por el Castilla más importante en 1901 fue «El sexteto catalán», formado por músicos ciegos catalanes que, acompañados muchas veces del propio Manuel Mezquita, recibieron muy buenas críticas del público del favorecido café:

En el café Castilla dieron anoche el uiltimo concierto los notables artistas ciegos que forman el sexteto catalán. En todos los números que obtuvieron magistral ejecución, fueron muy aplaudidos, lo mismo que el maestro señor Mezquita que les acompañó al piano ${ }^{20}$.

Por otra parte, es digno de señalar también que, durante los once años de actividad que recoge el presente artículo, el concierto solista o las agrupaciones instrumentales, fueron las únicas tipologías de espectáculo en el Castilla, alejándose de las tradicionales cupletistas y diferentes números de variedades que encontramos en esta misma etapa, en el café del Siglo, por ejemplo.

El sexteto catalán permaneció en Salamanca hasta la primera semana de Noviembre, siendo sustituidos en el Castilla por los concertistas Ibar y Rubio (piano y violín), de paso hacia Madrid, con un repertorio parecido también recogiendo excelente crítica.

Otros músicos y agrupaciones importantes que compartieron cartel en el Castilla en meses sucesivos, junto con el permanente Manuel Mezquita, fueron el profesor de guitarra señor Gayarre, con un repertorio importante en género clásico y flamenco, los

19 ALVAREZ GARCÍA, F. J.: «Bandas musicales en Salamanca a comienzos del S. XX. con la prensa local como fuente principal» Ediciones Universidad Pontificia de Salamanca. Salamanca, 2012.

20 «Crónica Local y Provincial», El Adelanto -Salamanca-, 7 de Noviembre de 1901; B.G.U.S. 
arpistas hermanos Hernestini y Leopoldini, el reputado concertista de guitarra Esteban Juez (que también pasó por otros cafés de la ciudad), o el dúo de tiple y tenor de «El dúo Franco Espańol». Todos ellos obtuvieron una muy buena acogida:

\begin{abstract}
En el Café de Castilla continúa todas las noches dando conciertos el aplaudido guitarrista, señor Juez, llamando poderosamente la atención por lo notablemente que interpreta las piezas de su escogido repertorio. Según noticias fidedignas sabemos que continuará tocando a las mismas horas algunos dias más ${ }^{21}$.
\end{abstract}

Tras la muerte del pianista Manuel Mezquita en Octubre de 1903, o bien la tradición musical se perdió considerablemente en el café o el tipo de actividad musical no fue considerado significativo como para ser reseñado en prensa ya que no volvemos a encontrar referencia musical en el Castilla hasta Enero de 1906, cuando el bajo señor Brandón, participó en un concierto junto a dos conocidos jóvenes salmantinos. Desde entonces y hasta el final de la década, la actividad musical no se interrumpió en el tiempo más allá de unas semanas o meses (sobre todo en la estación más calurosa), celebrándose conciertos muchas noches del año. Algunos de estos músicos y agrupaciones fueron: el profesor de guitarra, Antonio Martín, conocido por «El Lucecita», el cuarteto de profesores Alonso e hijos, la rondalla «Bohemios», dirigida por Eladio González Cabrera, Manuel Ventura, tenor del Orfeón Salmantino y reputado cantante salmantino, la Rondalla Salmantina dirigida por Bernardo G. Bernal y, destacando en tiempo y número de participaciones sobre todos ellos, la Tuna Escolar que, cada ańo, escogía el café Castilla como centro de reunión y salón para muchos de sus conciertos, además de contratar su hotel para alojar a los estudiantes, que de otras universidades y ciudades, llegaban invitados a Salamanca.

Por otra parte algunas referencias en prensa, nos llevan a pensar que no sólo había música en el Castilla cuando la agrupación o músico eran reseñados en el periódico sino que, habitualmente, como en la época de Manuel Mezquita, algún músico, dúo o trío, amenizaba las noches en el local:

Accediendo a los deseos manifestados por algunos aficionados al bel canto, asiduos concurrentes al café Castilla, en el concierto de piano y violín que, como todas las noches, tendrá lugar en dicho establecimiento, el miércoles próximo cantará algunas romanzas de ópera y zarzuela $(. . .)^{22}$.

También es digno de destacar en el Castilla el paso por su café del consagrado Sexteto del Pasaje (con algunas variantes en su formación), conocido en este local como

$\overline{21}$ «Crónica Local y Provincial», El Adelanto -Salamanca-, 17 de Junio de 1902; B.G.U.S.

22 «Salamanca», El Lábaro -Salamanca-, 1 de Julio de 1907; B.G.U.S. 
Sexteto Salmantino. La agrupación fue contratada para los meses de Febrero y Marzo de 1908 y la recepción crítica fue tan buena como la recibida en el café Pasaje:

La dueña de este acreditado establecimiento ha contratado un sexteto musical, compuesto de conocidos profesores de esta localidad, para que durante los meses de febrero y marzo de conciertos todas las noches de nueve a once. El sexteto está compuesto en la forma siguiente: Primer violin: Jacinto Rodríguez. Segundo violin: Lorenzo Milla. Viola: Fernando Rodríguez. Violonchelo: Enrique Mezquita. Contrabajo: Manuel Rodriguez. Pianista: Luis Martín. El primer concierto tendrá lugar el tres de febrero. Felicitamos a doña Juana Moreno por su excelente acuerdo ${ }^{23}$.

La popularización del cinematógrafo también llegó al Castilla y aunque fue instalado en 1907, no fue hasta 1910 cuando su uso se popularizó. Suponemos que esta circunstancia, modificó la frecuencia y tipología de espectáculo musical, viéndose relegada a un segundo plano por la "electricidad mágica»:

\section{CAFÉ LA PERLA}

Situado en los primeros números impares de la calle del $\operatorname{Prior}^{24}$, y haciendo esquina con la calle del Prado, muy cerca del café el Siglo (luego Variedades), el café «la Perla», contaba con dos plantas y era un lugar bastante concurrido, aunque no especialmente popular por sus participaciones musicales:

(...) Un poco más allá, haciendo esquina con la calle del Prado, habia otro café, "La Perla» (después Simu). Este café estaba dividido en dos por una especie de balaustrada; una parte con camareros, y la otra, más pequeña, con camareras, que sin embargo era una cosa formalita, pues el trato con ellas tenía un límite. Alli no habia desvergüenzas. Aquel café fue muy nombrado (... $)^{25}$.

En la primera década del S. XX., no contamos más que con tres referencias de participaciones musicales (cinco noticias en total), correspondientes a Enero y Febrero de 1906 y a Enero de 1907. Este hecho no significa que la actividad musical se redujera a estas expresiones, pero sí es significativo el reducido número existente de las mismas, en comparación con la actividad de otros cafés como el Pasaje, Castilla o Variedades. Así, las intervenciones más significativas, fueron las siguientes, por orden cronológico.

23 «Conciertos en el Café Castilla», El Adelanto -Salamanca-, 1 de Febrero de 1908; B.G.U.S.

24 Según actas de los años 1889-1893 de la Cámara de Comercio de Salamanca.

25 ANSEDE, C. R., De la Salamanca de ayer: usos, costumbres, recuerdos... Salamanca: Diputación de Salamanca, 1969. 
Participación del bajo señor Brandón:

Esta noche a las nueve dará un concierto en el Café la Perla el señor Brandón que tantas simpatias tiene entre los salmantinos ${ }^{26}$.

Participación de la cupletista Sara Mart:

A los conciertos celebrados en el café de la Perla las noches del domingo y lunes por la aplaudida coupletista Sara Mart, acudió numeroso público que hizo repetir casi todos los números que constituian el programa y aplaudió calurosamente a la artista ${ }^{27}$.

Participación de la Rondalla «Bohemios»:

Anoche dio concierto la notable rondalla Bohemios que dirige don Eladio González en los Cafés del Suizo y Perla siendo muy aplaudidos por la maestría con que ejecutaron las piezas teniendo que repetir el coro de "Bohemios» habiendo sido obsequiada con dulces, licores y habanos y una gratificación en metálico (... $)^{28}$.

\section{CAFÉ SUIZO}

El céntrico Café Restaurant Suizo, además de figurar entre los locales más populares de esparcimiento salmantino, es reseńado en prensa, en multitud de ocasiones, como centro donde la actividad musical juega un papel importante. Al igual que el Café Castilla, el Suizo está muy vinculado con la tradición estudiantil, así como con sus tunas y rondallas. De hecho, su reservado ha servido, en múltiples ocasiones, como local de ensayo para sus populares agrupaciones de temporada. Por temporadas y dicho de forma coloquial, se podría afirmar que el Suizo era como la segunda casa de los tunos, a la que acudían tras la «dura» jornada laboral. De hecho, los salones del Café eran utilizados por la Tuna Escolar incluso para realizar las tradicionales juntas generales.

Después del concierto que anoche celebró la simpática Tuna Escolar que dirige el reputado violinista don Eloy Andrés, en el café del Pasaje, los jóvenes que la componen, vistiendo el clásico traje de estudiante, marcharon al Suizo en cuyo amplio salón, echados sobre los divanes unos, sentados en torno de los veladores otros, pasaron la noche en completa armonia hasta las cuatro de la madrugada, hora en la que se

\footnotetext{
26 «Noticias», El Adelanto -Salamanca-, 11 de Enero de 1906; B.G.U.S.

27 «Noticias», El Adelanto -Salamanca-, 6 de Febrero de 1906; B.G.U.S.

28 «Noticias», El Adelanto-Salamanca-, 29 de Enero de 1907; B.G.U.S.
} 
dirigieron a la estación del ferrocarril con el objeto de tomar el tren que les ha de conducir a Oporto ${ }^{29}$.

$\mathrm{Al}$ margen de la actividad estudiantil, los conciertos musicales estaban, como en el Pasaje, Siglo o Variedades, a la orden del día. Músicos, agrupaciones (locales o foráneas), eran contratados como aliciente a una clientela, que gustaba de la buena música y que acudía, sobre todo los meses de frío, a disfrutar de ella. Al igual que en el Siglo, el Suizo albergaba de vez en cuando pequeños bailes organizados por diferentes sociedades, que alquilaban el salón principal para divertirse por ferias, carnavales o Navidad. Como sabemos tras el estudio del café Castilla, comenzamos 1900 con un pianista veterano en el Siglo: Manuel Mezquita. De hecho, la primera referencia en prensa al café, nombra al profesor de la mano del notable solista de oboe, Narciso Navascués (que posteriormente tendrá tanta relevancia en los conciertos ofrecidos para la Sociedad Filarmónica Salmantina, aún inexistente). La Tuna escolar ya aparece en los primeros compases de $1900 \mathrm{y}$, junto con la rondalla «Los Hijos del Trabajo», será la agrupación que más frecuente el local:

\begin{abstract}
En el Círculo estuvo la "Tuna escolar» que fue obsequiada por la junta. Antes habia tocado en el Suizo" ${ }^{30}$. "Esta noche asistirá al "Café Suizo» la Rondalla "Hijos del Trabajo». Interpretará aplaudidas piezas ${ }^{31}$.
\end{abstract}

$\mathrm{Al}$ margen de las rondallas y tunas estudiantiles, en 1901 también destacaron por su actividad musical en el café, los reputados artistas Lucio Rodríguez, pianista y profesor y Eloy Andrés, violinista, director por esas fechas de la rondalla «Los hijos del trabajo» (muy vinculada a este local) Su recepción y acogida por parte del público fue buena. Hasta 1905, las referencias en prensa a la actividad musical en el Café Suizo, se limitan, desde este momento, a la fructífera rondalla «Los Hijos del Trabajo», dirigida por Eloy Andrés, y a la propia Tuna Escolar que, entre otros acontecimientos, recibirán a sus compañeros de la tuna Valladolid-Coimbra en las instalaciones del Suizo, en Febrero de 1902. En Agosto de 1902 el local realiza reformas colocando un nuevo decorado. El remozado café se reabre, cómo no, con la rondalla «Hijos del Trabajo», dirigida por Eloy Andrés:

Se ha terminado el nuevo decorado de este establecimiento (...). La inauguración del establecimiento con las reformas introducidas, tendrá lugar mañana 20, por la noche, con un escogido concierto que ejecutará el piano y la rondalla "Hijos del Trabajo»"32.

\footnotetext{
29 «Noticias», El Adelanto -Salamanca-, 7 de Febrero de 1907; B.G.U.S.

30 "Crónica Local y Provincial», El Adelanto -Salamanca-, 27 de Febrero de 1900; B.G.U.S.

31 «Crónica Local y Provincial», El Adelanto -Salamanca-, 15 de Febrero de 1901; B.G.U.S.

32 «Crónica Local y Provincial», El Adelanto -Salamanca-, 19 de Agosto de 1902; B.G.U.S.
} 
Aunque suponemos que los conciertos de la rondalla «Los Hijos del Trabajo», de la Tuna escolar y los de las participación de algún que otro músico, no se interrumpieron de la noche a la mańana, la realidad es que no volvemos a encontrar reseña periodística musical sobre el Suizo hasta Junio de 1905, cuando los hermanos Avilés acompañados por Eloy Andrés y el pianista Luis Martín, son anunciados para dar una serie de conciertos. Tras una pausa informativa hasta Enero de 1907, cuando El Adelanto nos reseńa un concierto de la rondalla «Bohemios», dirigida por Eladio González, la misma noche en la que compartió escenario con el café la Perla. Desde 1907 hasta 1910, encontramos bastantes referencias a la participación administrativa y musical de la Tuna Escolar, dirigida, esta vez, por Eloy Andrés que, imaginamos, estaba unido de manera sentimental al local y a sus dueños, ya que su nombre y el del café aparecen reseñados juntos con mucha frecuencia, al margen de su propia participación en la estudiantina.

\section{(...) Para la constitución de la tuna, se celebrará esta noche, a las 7, una reunión en el res- ervado del café Suizo donde la Comisión organizadora ha invitado a todos los estudiantes de las facultades, Instituto, escuela normal y carreras especiales, que deseen pertenecer a la estudiantina ${ }^{33}$.}

\section{NOVELTY}

Fundado a finales de 1905 por Federico y Vicente García Martín, el Café Novelty, el único de los reseńados en prensa que ha llegado (con apreciables modificaciones), hasta nuestros días convirtiéndose, desde muy pronto, en referente musical en la Salamanca de comienzos del S. XX. El amplio café se situó en el número 2 de la Plaza Mayor, junto a la actual Casa Consistorial, en el espacio que ocupaba un antiguo almacén de tripas. Esta situación privilegiada lo convirtió, desde prácticamente su inauguración, en centro neurálgico salmantino, a la altura de cafés como el Castilla, Pasaje o el Siglo. Como café y lugar de reunión de la alta sociedad salmantina y sobre todo como parapeto y bastión donde empaparse del ambiente que la plaza proporcionaba, el café fue cobrando relevancia desde prácticamente el año de su inauguración contando, a nivel musical, con una actividad relevante y, sobre todo, regular, desde 1906. Precisamente la primera referencia musical al local que encontramos en prensa, nos habla del papel de punto de encuentro con la Plaza Mayor, en este caso con la banda "el $1^{\circ}$ de Mayo", en uno de sus habituales conciertos estivales.

33 «Tuna Escolar», El Adelanto -Salamanca-, 8 de Noviembre de 1910; B.G.U.S. 
(...) Cinco audiciones de la insustituible banda El $1^{\circ}$ de Mayo (sin tómbola), vueltas y más vueltas por la Plaza, "barricadas" en Novelty y Pasaje, grupos de personas "muellemente» acomodadas en las sillas de la acera del Correo, idilio de niñeras con soldados, carreras de golfos por los jardines $(. . .)^{34}$.

En Enero de 1907, el local aparece ya dentro del circuito escénico-musical de los cafés salmantinos, incorporando espectáculos en su salón, similares a los del Castilla, Variedades, Suizo y Perla. Por ejemplo, la rondalla «Bohemios» de Eladio González, tras actuar en el Suizo y Perla, pasa ahora, de esta forma, a tocar en el Novelty. A finales de 1907, encontramos la primera referencia a una actividad musical continuada, en la tipología de «veladas musicales». De la mano de Jesús Pinedo, reconocido pianista mirobrigense de adopción, varias agrupaciones musicales comienzan a amenizar el café en las clásicas veladas nocturnas. De alguna manera se podría decir que Jesús Pinedo fue al Novelty, lo que Manuel Mezquita supuso para el Suizo/Castilla.

\begin{abstract}
Anoche se inauguraron las veladas musicales que los propietarios del elegante café Novelty han organizado en obsequio a la distinguida concurrencia que al mismo acude. El programa anunciado fue ejecutado admirablemente por el notable pianista señor Pinedo, y las numerosas personas que al lindo café concurrieron salieron altamente complacidas ${ }^{35}$.
\end{abstract}

Hasta finales de Febrero de 1908, un quinteto sin identificar, pero seguramente comandado por el propio Jesús Pinedo, fue el encargado de amenizar las frías tardes de invierno. Lo que sí tenemos claro es que este quinteto nada tenía que ver con los integrantes del sexteto del Pasaje (luego Salmantino), ya que, precisamente en este periodo amenizaban el Castilla. Es muy probable, por otra parte, que alguno de los miembros del Septimino que el invierno siguiente amenizarán el café, fuera componente, esa precisa campańa, del propio quinteto. Los programas de los conciertos, curiosamente, difieren bastante de los encontrados en el resto de cafés-concierto, concretamente en la inclusión de repertorio español y, sobre todo, zarzuelístico, que prácticamente no aparece en la relación de obras catalogadas. Los conciertos, además, son de tarde y noche, normalmente.

Como en el resto de cafés, el público valora muy positivamente las veladas musicales y la afluencia al local es considerablemente mayor durante las temporadas en la que alguna agrupación participa. Al contrario que el Pasaje, el Novelty ofrecía música sobre todo en la temporada de invierno, así que no encontramos actividad musical hasta la llegada de los primeros fríos, ya durante la temporada siguiente, con la participación de un trío anónimo de concertistas femeninas. Al comienzo de la campaña, se realizaron reformas instalando una nueva calefacción de vapor.

\footnotetext{
34 "Crónica diaria», El Adelanto -Salamanca-, 20 de Julio de 1906; B.G.U.S.

35 «Noticias», El Adelanto-Salamanca-, 16 de Noviembre de 1907; B.G.U.S
} 
Ha quedado instalada en Novelty la calefacción por vapor, que reparte agradable y uniforme temperatura; buen abrigo para estos atardeceres de invierno que los dueños del elegante café piensan amenizar con el trio de profesoras concertistas ${ }^{36}$.

Pero sin duda la agrupación más relevante de la nueva temporada, será la comandada por el contrabajista Gustavo Benoit, conocida como el «Septimino del Novelty», que amenizará el café desde Diciembre de 1908 hasta Mayo de 1909. Estaba compuesta por: Gustavo Benoit, contrabajista y director; Louis Borrel, saxofón; Alfredo Ronland, violinista; Jesús Pinedo, pianista; Carlota Morell, segundo violín; Luisa Benoit, violín ripiano y Mademoiselle Delacroix, primer violín. Los programas, en la línea de la anterior temporada, eso sí, añadiendo repertorio de la tierra, con coros de zarzuela, principalmente. La recepción por parte del público fue muy buena consiguiendo hacer de esta campańa la más larga, de entre las documentadas en un café durante la primera década del S. XX., (seis meses consecutivos). En Mayo, y sin prácticamente interrupción en los recitales, es contratada para amenizar las tardes y noches primaverales, la arpista Lolita Vercruysee que, junto con el asiduo Jesús Pinedo al piano, permanecerán toda la temporada, hasta la llegada del verano. Las críticas a sus conciertos, muy positivas y los programas, muy variados, sin prácticamente repetición de obras en los mismos. En Noviembre de 1909, tras el parón veraniego (donde la mayor parte de la actividad musical se realiza al aire libre), toma el relevo en el Novelty, para los conciertos de la temporada de otońo-invierno, una nueva agrupación que tiene como denominador común con el Septimino, la participación del pianista Jesús Pinedo, la violinista Luisa Benoit y el director, Gustavo Benoit.

\begin{abstract}
(...) Como en anteriores años, Novelty será el centro de reunión de la buena sociedad salmantina. Conciertos sinfónicos, por la notable orquesta de señoritas cosmopolitas. Director: don Gustavo Benoit, Mademoiselle Banche Prat, (violin solo), premio de Paris; Madame Louise Benoit (violin ripiano), premio de Bordeaux; mademoiselle Jeannette Froome, (violonchelo), premio de Londres; mademoiselle Muriel Fife (viola), premio de Londres; mademoiselle Cecile Prat (pianista), premio de Nantes; don Jesús Pinedo (harmonium), premio de Madrid ${ }^{7}$.
\end{abstract}

La nueva agrupación, que obtuvo, como el Septimino, un gran éxito en todas sus presentaciones, era conocida como el «Sexteto de las Señoritas Cosmopolitas» y se mantuvo en programa hasta Enero de 1910. La más aplaudida de todas ellas, fue la chelista Jeannette Froome. Los programas, amenos y del gusto del público, escatimando bastante en "folclorismos», canción española y zarzuela. La fantasía sobre ópera y las adaptaciones sobre repertorio romántico, los recursos más utilizados por la agrupación.

\footnotetext{
36 «Gacetilla Local», El Lábaro -Salamanca-, 9 de Diciembre de 1908; B.G.U.S.

37 «Los conciertos del Novelty», El Adelanto -Salamanca-, 2 de Noviembre de 1909; B.G.U.S.
} 
Los señores García, dueños del café, intentaron traer, para concluir la temporada invernal, a las notables violinistas hermanas Moreu, artistas del recién incendiado Teatro de la Zarzuela madrileńo, pero, por lo menos hasta Diciembre de 1910, fecha de la conclusión del presente estudio, no llegaron a actuar. Durante 1910, no poseemos ninguna información de actividad musical y suponemos que la temporada de invierno este año, se retrasó hasta Enero.

\section{BAR SALMANTINO}

El 16 de Mayo de 1910 se inaugura, con la participación de la banda «El 1º de Mayo», el bar Salmantino, local situado en la Plaza de la Libertad que, acogerá, lo que resta de año (en muy contadas ocasiones), algún tipo de actividad musical, eso sí, en cuanto a número, muy lejos de la mencionada en los cafés/salas de variedades ya estudiados. De hecho, la única participación que encontramos, al margen de las audiciones de gramófono que el café ofrecía, es la de un quinteto formado por ciegos y sordomudos (del propio colegio nacional de ciegos y sordomudos de Madrid), que actuó, por lo menos en dos ocasiones, en Agosto de 1910, obteniendo una buena crítica.

En el ideal bar salmantino se celebró anoche un gran concierto por un quinteto del colegio nacional de sordomudos y ciegos, que hizo las delicias del público. Esta noche, de nueve a doce, darán los mismos ciegos otro concierto vocal e instrumental, que seguramente será tan del agrado del público como el de anoche. Los conciertos se celebran en la plazuela de la libertad y los intermedios sedan escogidas piezas del gramófono, a cuyo efecto se hallara iluminada la plazuela como los dias de moda ${ }^{38}$.

Por lo demás, las únicas noticias en prensa al bar Salmantino encontradas, se refieren a la realización de audiciones musicales, pero a través de gramófono, sin una participación musical en directo. Es probable que la actividad musical del bar se consolidase a partir de 1911.

\section{BIBLIOGRAFÍA}

ALVAREZ GARCÍA, F. J.: «La actividad musical en Salamanca a través de la prensa local. 1900-1910». Tesis Doctoral. USAL: Departamento de Historia y Ciencias de la Música. Salamanca, 2009.

ALVAREZ GARCÍA, F. J.: «Músicos en Salamanca a comienzos del S. XX». Publicaciones Universidad Pontificia de Salamanca. Salamanca, 2012.

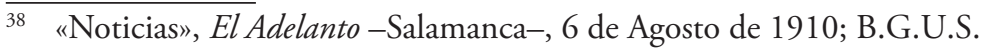


ALVAREZ GARCÍA, F. J.: «Bandas musicales en Salamanca a comienzos del S. XX. con la prensa local como fuente principal» Ediciones Universidad Pontificia de Salamanca. Salamanca, 2012.

ANSEDE, C. R.: «De la Salamanca de ayer: usos, costumbres, recuerdos...» Salamanca: Diputación de Salamanca, 1969.

CASARES RODICIO, E.: «Diccionario de la zarzuela, España e Hispanoamérica». Madrid: Instituto Complutense de Ciencias Musicales, 2003.

CONESA, M.: «La Salamanca de los Gombau». Junta de Castilla y León. Salamanca, 1996.

FERNÁNDEZ GARCÍA, E.: «León y su vida escénica en la segunda mitad del S. XIX». Tesis Doctoral. UNED. Departamento de Literatura Española y de Teoría de la Literatura. Madrid, 1997.

GARCÍA LABORDA, J. M.: «La Sociedad Filarmónica de Madrid. Contexto histórico y valoración del repertorio». Universidad de Salamanca. Salamanca, 2006.

KENT, C.: «El perfil de Salamanca». Salamanca 2005, Plaza Mayor de Europa, 2005. 